\title{
Na Medicina e no Direito Como se Rompe um Paradigma?
}

\begin{abstract}
Fabiana Marion Spengler
Bolsista de Produtividade em Pesquisa do CNPq (Pq2). Pós-doutora em Direito pela Università degli Studi di Roma Tre, em Roma na Itália, com bolsa CNPq (PDE). Doutora em Direito pelo Programa de Pós-Graduação stricto sensu da Universidade do Vale do Rio dos Sinos - Unisinos - RS, docente dos cursos de Graduação e Pós-Graduação lato $e$ stricto sensu da Unisc, coordenadora do Grupo de Pesquisa "Políticas Públicas no Tratamento dos Conflitos" vinculado ao CNPq. Coordenadora da Rede de Pesquisa em Direitos Humanos e Políticas Públicas - REDIHPP. fabiana@unisc.br
\end{abstract}

\section{Fernando Augusto Marion Spengler}

Acadêmico do curso de Medicina da Universidade de Santa Cruz do Sul (Unisc). Integrante da Liga de Neurologia da Unisc. Representante do Departamento Universitário da Associação Médica do Rio Grande do Sul (Amrigs). fernandoamspengler@gmail.com.

O presente texto tem por tema a mudança do atual paradigma jurídico brasileiro de tratamento dos conflitos. 0 problema de pesquisa que se pretende responder é: Ao discutir a mudança do atual paradigma jurídico de tratamento dos conflitos sociais é possível tecer comparações com a mudança do paradigma médico de controle e prevenção de doenças infecciosas acontecido na metade do século 18 ? O objetivo é analisar a necessária mudança do atual paradigma jurídico de tratamento dos conflitos sociais comparando-a com a mudança do paradigma médico de controle e prevenção de doenças infecciosas acontecido na cidade de Viena. A hipótese apresentada, e ao final da pesquisa comprovada, mostrou-se afirmativa no sentido de que a mudança de paradigma médico de Viena, no ano de 1847, pode sim ser usada comparativamente para informar/fomentar a necessária mudança do atual paradigma jurídico de tratamento dos conflitos no Brasil. O método de pesquisa utilizado foi o dedutivo.

Palavras-chave: Assepsia. Tratamento de conflitos. Crise. Paradigma. Cultura jurídica. Mediação.

\section{IN MEDICINE AND LAW: HOW TO BREAK A PARADIGM?}

\section{ABSTRACT}

The text has as its theme the change of the current Brazilian legal paradigm for the treatment of conflicts. The research problem that is intended to answer is: when discussing the change of the current legal paradigm of social conflicts treatment is it possible to compare it with the change in the medical paradigm of control and prevention of infectious diseases in the middle of the eighteenth century? The objective is to analyze the necessary change of the current legal paradigm of treatment of social conflicts comparing it with the change of the medical paradigm of control and prevention of infectious diseases that happened in the city of Vienna. The hypothesis presented, and at the end of the research proved, affirmatively is in the sense that the medical paradigm change of Vienna in the year 1847 can be used comparatively to inform/foster the necessary change of the current legal paradigm of conflict resolution in Brazil. The research method is the deductive one.

Keywords: Asepsis. Conflict management. Crisis. Paradigm. Legal culture. Mediation. SUMÁRIO

1 Introdução. 2 A Conduta Social de Ontem, de Hoje e de Amanhã: afinal, o que é um paradigma? 3 A Crise de Ontem, de Hoje e de Amanhã: o que é preciso para quebrar um paradigma? 4 De Ontem para Amanhã: a necessária/ salutar quebra de paradigmas. 5 Para Hoje? Para Amanhã? Depois da Crise um Outro Paradigma? 6 Conclusão. 7 Referências. 


\section{Introdução}

É de conhecimento comum, cientificamente comprovado, ${ }^{1}$ que o Judiciário brasileiro já não consegue (se é que algum dia conseguiu) responder, em termos qualitativos e quantitativos, às demandas judiciais a ele direcionadas. Diante dessa realidade, o Conselho Nacional de Justiça (CNJ) deu o primeiro passo na busca de opções que fizessem a prestação jurisdicional mais acessível, econômica e célere.

Assim, em 2010 foi criada a Resolução 125 do CNJ com o objetivo de estimular e regulamentar o tratamento ${ }^{2}$ dos conflitos por vias não adversariais, mediante a instituição de políticas públicas de pacificação social. Tal Resolução nasceu em um cenário social de extrema conflitividade e determina a competência do Conselho Nacional de Justiça para organizar programas com o objetivo de promover ações de incentivo à autocomposição de litígios e à pacificação social por meio da conciliação e da mediação.

Mais bem amadurecida a Resolução sofreu duas emendas (datadas de 2013 e 2016) e foi seguida pela promulgação da Lei no 13.105/2015 - o atual Código de Processo Civil - e pela Lei 13. 140/2015 - considerada o marco legal da mediação. Posteriormente, a mediação trabalhista foi instituída pela Resolução 174/2016 do Conselho Superior da Justiça do TrabaIho (CSJT). Todas essas inciativas instituíram os meios autocompositivos, entre eles a mediação e a conciliação, como políticas públicas de tratamento adequado de conflitos, objetivando a pacificação social e uma mudança de cultura/paradigma, substituindo o processo/guerra pela consensualidade/pacificação.

Em contrapartida, a Medicina passou por uma grande mudança de paradigma que instituiu, em um primeiro momento, a cultura de lavar as mãos como meio de promover a assep$\mathrm{sia}^{3}$ e evitar doenças infecciosas e promoveu um novo padrão. Esse processo, contudo, levou muito tempo e aconteceu ainda no século 18 , mediante a observação criteriosa e as descobertas do médico chamado Semmelweis. ${ }^{4}$

\footnotetext{
O fato de que o Judiciário não está dando conta de atender a sua demanda pode ser comprovada com a publicação anual do Relatório Justiça em Números, do Conselho Nacional de Justiça - CNJ. O último relatório aponta para uma taxa de congestionamento (que é o "indicador que compara o que não foi baixado com o que tramitou durante o ano-base - soma dos casos novos e dos casos pendentes iniciais)" de mais de 70\%. (<http://www.cnj.jus.br/programas-e-acoes/pj-justica-em-numeros>. Acesso em: 13 out. 2016, p. 37).

2 Aqui, utilizar-se-á a expressão "tratamento" ao invés de "solução/resolução" de conflitos uma vez que: a) Resolução 125 do CNJ adotou essa expressão ao se referir à mediação e à conciliação como "Política Judiciária Nacional de tratamento dos conflitos de interesse"; b) porque se entende que a expressão "tratamento" torna-se mais adequada enquanto ato ou efeito de tratar, lidar, administrar, de discutir o conflito buscando uma resposta satisfativa; c) a expressão tratamento aqui não vem utilizada como ato de tratar no sentido de medida terapêutica médica ou psicológica; d) por fim, utiliza-se tal expressão, nas palavras de Bobbio, por entender que os conflitos sociais não são "solucionados" pelo Judiciário no sentido de resolvê-los, suprimi-los, elucidá-los ou esclarecê-los. Isso porque "a supressão dos conflitos é relativamente rara. Assim como relativamente rara é a plena resolução dos conflitos, isto é, a eliminação das causas, das tensões, dos contrastes que os originaram (quase por definição, um conflito social não pode ser "resolvido")." É possível decidir conflitos aos olhos do Direito, dificilmente se alcança solucioná-los ou resolvê-los (BOBBIO; MATTEUCCI; PASQUINO, 2004. p. 228). Nesse sentido, ver também Bolzan de Morais e Spengler (2012).

3 “Esse termo advém do grego $a$ - negação + séptico - putrefação, significando ausência de matéria séptica, estado livre de infecção. Trata-se de método que impede, especialmente por meios físicos e químicos, a entrada de microrganismos patogênicos no corpo humano; método físico (e também químico) para prevenção do desenvolvimento de infecções mediante a destruição dos agentes infecciosos; impedimento de penetração de microrganismos em local que não os contenha. Um local estéril" (MARQUES, 2005, p. 225)

4 Ignaz Semmelweis nasceu em Budapeste, no dia 10 de julho de 1818. Em 2018 seu nascimento completa 200 anos e suas descobertas, agora largamente adotadas, continuam impactando a área médica.
} 
Tendo como pano de fundo as alterações médicas promovendo a assepsia e a criação de políticas públicas de tratamento dos conflitos, o presente texto tem por tema a mudança do atual paradigma jurídico brasileiro de tratamento dos conflitos, necessária, porém tão difícil de se concretizar. Então, o problema de pesquisa ao qual se pretende responder é: Ao discutir a mudança do atual paradigma jurídico de tratamento dos conflitos sociais é possível tecer comparações com a mudança do paradigma médico de controle e prevenção de doenças infecciosas acontecido na metade do século 18 ? De que modo essa comparação pode se dar e o que poderá ser aproveitado daquela reviravolta médica?

Por conseguinte, o objetivo do presente estudo está centrado em analisar a necessária mudança do atual paradigma jurídico de tratamento dos conflitos sociais comparando-a com a mudança do paradigma médico de controle e prevenção de doenças infecciosas acontecido na cidade de Viena.

A hipótese apresentada e que ao final da pesquisa foi comprovada mostrou-se afirmativa no sentido de que a mudança de paradigma médico acontecido para fins de controle e prevenção de doenças, em Viena, no ano de 1847, pode sim ser usada comparativamente para informar/fomentar a necessária mudança do atual paradigma jurídico de tratamento dos conflitos sociais.

Para fins de cumprir com o proposto o método de abordagem utilizado foi o dedutivo (VENTURA, 2000), partindo da relação entre argumentos gerais, denominados premissas, para argumentos particulares, até se chegar a uma conclusão. Como método de procedimento foi utilizado o monográfico, a partir da leitura e fichamentos de fontes bibliográficas ligadas ao tema da pesquisa.

Assim, no primeiro item o presente texto aborda a conduta social como elemento de construção da cultura; esta última, por sua vez, é mais ampla e se reflete no paradigma, que é o modelo a ser seguido. Adiante o texto analisa a mudança de paradigma como mola propulsora de novas construções e da instituição de uma outra cultura, porém para mudar um paradigma é preciso coragem e uma atitude crítica e inconformista.

Na sequência discute-se a necessária e salutar quebra de paradigma na Medicina e no Direito colacionando a história do médico Semmelweis e suas desventuras na criação de novos modelos de comportamento. O último item analisa as crises da jurisdição brasileira que são fruto da crise do Direito e que apontam para uma mudança na cultura jurídica que somente poderá acontecer a partir da necessária quebra do paradigma atual.

\section{A Conduta Social de Ontem, de Hoje e de Amanhã: afinal, o que é um paradigma?}

A conduta humana se diferencia e se adapta - e é fator de adaptação - (d)a evolução social. Essa afirmativa pode ser constatada na leitura de sociólogos importantes, tais como Norbert Elias, que na obra A Sociedade de Corte (2001) analisa a sociedade francesa concluindo que sua formação foi ombreada por uma civilização que se baseou nos padrões da classe superior, evidenciando uma significativa regulação das expectativas e o aumento do controle social. Por conseguinte, Elias apontava para padrões sociais nos quais o vestir, o falar e o comportamento diferenciava rudes e refinados, traçando uma linha divisória (imaginária!) entre eles. 
Na sociedade descrita por Elias (2001) os padrões sociais analisados e vigentes nada mais eram que paradigmas utilizados para diferenciar quem pertencia ou não à Corte francesa. Esse é, pois, um exemplo de paradigma, que pode ser conceituado como "um conjunto de regras que definem a fronteira entre o que é certo e errado, entre o que é verdadeiro e o que é falso, entre o que se deve fazer e o que não se deve fazer" (CHIAVENATO, 1996, p. 21). Por isso, pode-se afirmar que um paradigma é aquilo que "estabelece um corredor de pensamento no qual este fica bitolado ao que existe dentro das faixas e dos limites permitidos" (1996, p. 21). Assim, um paradigma funciona como um modelo, um padrão, criado para definir o comportamento das pessoas.

Existe, porém, uma certa indefinição quanto às diferenças e ao uso do conceito de "paradigma" quando relacionado ao conceito de "cultura". Não obstante não serem sinônimos, são, algumas vezes, empregados como tal, demonstrando as dúvidas que o limite, um tanto quanto esfumaçado, dos dois termos oferece. Então, faz-se necessário diferenciar "cultura" e "paradigma".

Segundo o Dicionário On-line de Português, a palavra "cultura" é um substantivo feminino, possuindo como sinônimos: instrução, saber, cultivo, apuro, conhecimento. Significa, entre outras coisas:

Conjunto dos conhecimentos adquiridos; instrução: sujeito sem cultura. Conjunto dos hábitos sociais e religiosos, das manifestações intelectuais e artísticas, que caracteriza uma sociedade: cultura inca; a cultura helenística. Normas de comportamento, saberes, hábitos ou crenças que diferenciam um grupo de outro: provêm de culturas distintas. Expressão ou estágio evolutivo das tradições e valores de uma região, num período determinado: cultura católica. Aplicação do espírito a uma coisa: a cultura das ciências. Desenvolvimento das faculdades naturais: a cultura do espírito. Apuro, expressão de elegância: a cultura do estilo (2017).

É nesse sentido que, segundo Chase (2014, p. 26), precisamos de uma "noção de cultura que serve de atalho para se referir a pontos comuns em práticas, valores, símbolos e crenças de grupos particulares de pessoas". Nesse sentido, o autor afirma que adota o conceito de cultura que vincula pontos comuns que persistem no tempo, mas que, ele mesmo reconhece, dificilmente são eternos, ainda que largamente, mas não uniformemente, compartilhados por uma coletividade determinável.

Já a palavra "paradigma" é um substantivo masculino e possui como sinônimo: arquétipo, exemplo, modelo, norma, regra. Tem o seguinte significado:

Exemplo ou padrão a ser seguido; modelo: paradigma político. [Por Extensão] Padrão já estabelecido; norma: paradigma de mercado. [Gramática] Cujas formas vocabulares podem ser usadas como padrão ou modelo: o verbo amar segue o paradigma da primeira conjugação porque termina em "ar". [Linguística] Conjunto dos termos que podem ser substituídos, entre si, na mesma posição da estrutura da qual fazem parte (DICIONÁRIO..., 2017).

Partindo das definições anteriores, observa-se que a cultura é abrangente, apontando para algo mais amplo, uma construção sedimentada por anos de práticas sociais, advindas do cotidiano humano. O paradigma é mais estreito, limitando-se a um modelo, a um exemplo a ser seguido e definindo-se sempre a partir de uma cultura. O conceito de paradigma surgiu especialmente das experiências científicas de Thomas Kuhn. Kuhn percebeu que a ciência nada mais é do que uma tentativa de colocar a natureza dentro de esquemas conceituais for- 
jados na educação profissional. Assim, o cientista concluiu que a ausência de um paradigma faz com que os fatos significativos tenham pertinência ao desenvolvimento de uma ciência, uma vez que "o desenvolvimento da maioria das ciências têm-se caracterizado pela contínua competição entre diversas concepções de natureza distintas" (KUHN, 1991, p. 22).

Desse modo, e ainda de acordo com Thomas Kuhn, os "paradigmas são as realizações científicas universalmente reconhecidas que, durante algum tempo, fornecem problemas e soluções modelares para uma comunidade de praticantes de uma ciência" (1991, p. 13). Nesse contexto, um paradigma não depende de regras externas e se constitui em uma rede de adesões e compromissos, fazendo com que o cientista seja membro de uma determinada comunidade pela adesão a determinado paradigma.

Retomando a leitura de Elias (2001), um paradigma é um instrumento nas mãos da ordem dominante. Por conseguinte, todo paradigma é uma "forma particular de apelo a uma ou outra representação daquilo que chamo de sujeito e que é a afirmação - cujas formas são variáveis - da liberdade e da capacidade dos seres humanos de criar-se e transformar-se individual e coletivamente" (TOURAINE, 2011, p. 13) É assim que a ideia de paradigma pode ser exemplificada tanto com a luz quanto com a sombra. "Um paradigma valoriza tanto a liberdade quanto a alienação, tanto os direitos humanos quanto a obsessão pelo dinheiro, pelo poder e pela identidade" (2011, p. 13).

Os paradigmas delimitam o modo como a organização social funciona. Eles determinam suas características, suas interações comportamentais e suas expectativas. É por isso que qualquer mudança de cultura nessa organização social significa cambiamento de paradigmas ultrapassados. Mudar hábitos e costumes, alterar meios de se relacionar, de lidar com seus conflitos, de administrar interações sociais, pessoais e jurídicas, impõe, necessariamente, o repensar de certos paradigmas. Estes podem mudar porque o poder explicativo dos conceitos teóricos falha diante de desafios históricos. De repente, eles passam a ser vistos como não mais convincentes, embora nenhuma hipótese produzida com base em certo paradigma teórico tenha sido adulterada (ALTVATER, 1999).

Percebe-se então que muitas vezes a mudança de paradigma se dá pela decomposição social, quando "o elo entre o sistema e o ator se rompe, quando o sentido de uma norma para o sistema não corresponde mais ao sentido que ela tem para o autor". Por conseguinte, "tudo assume um duplo sentido e o indivíduo deseja afirmar-se por sua oposição à linguagem da sociedade" (TOURAINE, 2011, p. 77).

Essa conexão entre o sistema e o ator faz recordar as teorias de Dahrendorf (1991) quando este afirma que as expectativas e a atribuição de papéis ${ }^{5}$ sociais são prerrogativas essencialmente vinculadas a uma época e aos seus costumes. Assim, a categoria "papel social"

\footnotetext{
Para Dahrendorf (1991, p. 43-44), “Papel, pessoa, caráter e máscara são palavras que, apesar de provenientes de estágios diversos do desenvolvimento lingüístico, têm uma área de significado comum: o teatro. No drama, por exemplo, falamos de pessoas ou caracteres, cujos papéis são desempenhados pelo ator. Apesar de que atualmente este, em geral, não mais use máscara, também esta palavra tem a mesma origem. As associações que fazemos com estas palavras são múltiplas: 1) todas designam algo preexistente ao ator, algo existente fora dele; 2 ) este algo preexistente pode ser descrito como um complexo de modos de comportamento que, por sua vez, 3) com outras formas de comportamento forma o todo, apesar de ser uma parte (esta característica está presente nas palavras pars (latim) e part (inglês) que designam papel); 4) como estas formas de comportamento são impostas ao ator, o mesmo precisa aprendê-las para poder desempenhá-las; 5) do ponto de vista do ator, nenhum papel, nenhuma persona dramatis, é excludente; o ator pode aprender e desempenhar uma multiplicidade de papéis. [...] Por trás de todos os papéis, pessoas e máscaras, permanece o ator como algo específico, não afetado por estes."
} 
é entendida como uma forma de comportamento que está preestabelecido para uma regra de comportamento individual, "passando de um conceito para um conceito psicossociológico elementar" (DAHRENDORF, 1991, p. 46).

Os papéis sociais são exercidos por esses atores não só pela pressão/expectativa social, mas também devido a coações que são impostas aos indivíduos em todos os aspectos da vida. Esses papéis aos quais os atores sociais se encontram atrelados possuem uma pluralidade de formas e a eles é conectada uma multiplicidade de expectativas que não podem mais ser chamadas somente de sociais e sim de culturais. Isso significa que os atores sociais reagem à mudança de costumes, à aquisição do conhecimento, à evolução tecnológica e às mudanças políticas, entre outras.

Nestes termos, percebe-se que o paradigma que impõe uma determinada conduta social também é influenciado, de modo decisivo, pela cultura jurídica ${ }^{6}$ dos mesmos atores. 0 que se questiona, então, com base em Garapon e Papapoulos (2008, p. 7) é: "a cultura jurídica não seria senão a versão moderna do que se entendia outrora por tradição jurídica ou mentalidade de um povo?"Ao encontrar respostas (positivas!) para o questionamento anterior poder-se-ia referir que a atual cultura jurídica brasileira pertence à Civil Law; ${ }^{7}$ percebendo-se que o paradigma atual de resolução dos conflitos, fomentado por uma de uma cultura jurídica adversarial, atrelado ao processo e ao seu ritual, ${ }^{8}$ não atende mais à hodierna complexidade ${ }^{9}$ conflitiva, requerendo revisão e mudança.

\section{A Crise de Ontem, de Hoje e de Amanhã: o que é preciso para quebrar um paradigma?}

Partindo do anteriormente debatido constata-se que a sociedade brasileira baseia-se na cultura jurídica da Common Law, trabalhando com o paradigma adversarial, intimamente ligado ao processo que não responde de maneira adequada aos conflitos sociais. Diz-se, então, que o paradigma de resolução de conflitos representado pela prestação jurisdicional encontra-se em crise (SPENGLER, 2016).

\footnotetext{
Ao fazer referência à cultura jurídica Garapon e Papapoulos $(2008$, p. 6) afirmam que: "a cultura é aquilo que é dado, o "já presente", o sentido depositado no espírito dos membros de um mesmo povo, na maioria das vezes de modo inconsciente. A cultura trabalha sempre inconscientemente, devemos entendê-la como um instituidor. Por isso ela tem sua sede na mente dos atores (de todos) e não apenas na dos juristas. Essa entrada na cultura jurídica pelo viés da consciência jurídica seria apenas folclórica se nossas democracias não acolhessem um número cada vez maior de estrangeiros que não compartilham dos mesmos pressupostos culturais. Como um chinês pode compreender uma audiência no gabinete do juiz de menores? A situação das democracias contemporâneas, todas elas confrontadas com uma imigração massiva, confere a esta abordagem uma atualidade inédita."

7 Ainda que não seja objetivo desse texto esmiuçar as características, comparar as vantagens, as desvantagens e/ou semeIhanças entre a cultura jurídica da Civil Law e da Common Law, torna-se necessário referir que o Brasil pertence à primeira e que esta é, segundo Garapon e Papapoulos (2008, p. 247), mais democrática e menos tributária se comparada à segunda. Os autores apontam ainda que a cultura jurídica da Civil law é "mais racional, embora seja menos pragmática, e, em consequência, incessantemente ameaçada pela abstração e ineficácia."

8 "Rito é termo que vem da experiência religiosa e que terminou por fazer parte do léxico fundamental da antropologia". Assim, o rito indica o "conjunto de práticas linguísticas que transfere no campo da previsibilidade um mundo cheio de símbolos, expectativas, experiências que geram a angústia da incerteza" (RESTA, 2014, p. 11).

9 Importante é ressaltar que a expressão "complexidade" vem aqui utilizada como maneira de qualificar a sociedade atual, destacando os diversos elementos diferenciados que a compõem e que the conferem uma forma intrincada e multifacetada. Assim, não se pretende trabalhar com categorias da Teoria dos Sistemas, entre as quais está a "complexidade", sendo lá entendida como aquilo que "indica el hecho de que no todos los elementos de dicha unidad pueden estar simultáneamente en relación con elles mismos. Así, la complejidad significa que para actualizar las relaciones entre los elementos es necesaria una selección..." (CORSI; ESPOSITO; BARALDI, 1996. p. 43).
} 
Dá-se início à discussão delimitando os contornos da palavra crise, para, a partir dela, entabular a discussão proposta. A que noção de crise, porém, se faz referência ${ }^{10}$ Uma crise não é concebida exatamente da mesma maneira em áreas diversas. Assim, falar de crise em Filosofia, em História das Ciências, em Medicina, em Psiquiatria ou em Economia são coisas diversas. Existe, contudo, um conjunto de traços comuns a toda crise, desde que se situe a análise em um nível profundo, o das estruturas na maioria das vezes não aparentes, o das estruturas reais do fenômeno estudado. Por isso, "a crise aparece então como um momento no qual se inicia o jogo do par de oposição continuidade/ruptura" (ARNAUD, 1991, p. 171).

Isso posto, ao discorrer sobre continuidade/ruptura, ${ }^{11}$ é necessário supor uma "intervenção bastante forte para criar um risco de ruptura no seio de um estado de coisas, de uma 'ordem' ainda não contestada... ou pelo menos não colocada em questão". Diante de tal situação, não é suficiente dizer que "estamos em crise": convém, além disso, precisar em que medida a crise se revela ameaçadora numa intervenção determinada, que continuidade se encontra em perigo, de qual ordem ela é passível de arruinar a estabilidade (ARNAUD, 1991, p. 172).

Assim, pode-se afirmar que:

Uma crise é o estágio de conflito e confusão de um processo histórico de transformação que envolve três conjuntos inter-relacionados de contradições: políticas, econômicas e culturais. Tais contradições foram os diferentes agentes sociais a encontrar um novo paradigma para substituir os que estão causando a situação caótica. Nesse sentido, trata-se de uma crise de ocasião histórica para diferentes paradigmas surgirem e se engajarem num processo de competição feroz, formando coligações e contra coligações com base em algumas posições epistêmicas compartilhadas (MUSHAKOJI, 1999, p. 196).

Com relação à crise de qualquer paradigma e inclusive do atual modelo de tratamento de conflitos, observa-se que emerge quando não só "essa ou aquela resposta desse ou daquele cientista às questões colocadas pelo público não são satisfatórias, mas também quando são insuficientes ou mesmo ridículas" (ALTVATER, 1999, p. 110). Por conseguinte, a crise tem início quando "é impossível encontrar para um público mais amplo, as respostas científicas plausíveis para desafios reais" (ALTVATER, 1999, p. 110).

Retomando as lições de Thomas Kuhn (1991), o vocábulo "paradigma" não possui um sentido único, pois uma vez estabelecido, por um certo período de tempo, os cientistas desenvolvem noções e analisam os problemas dele advindos. Ao questionar o paradigma ado-

\footnotetext{
${ }^{10}$ Aqui é importante fazer uma definição precisa quanto ao conceito de "crise" ante a inflação atual do termo que se refere, num primeiro nível e ao mesmo tempo, à crise econômica, política, ideológica e às relações entre elas. Nesse sentido, Nicos Poulantzas delimita o conceito de crise em Economia como aquela que funciona, grosso modo, como purgas periódicas do capitalismo numa concepção burguesa ou como uma crise constante e reprodutiva de si mesma numa concepção mecanicista ou evolucionista. Quanto à crise política/ideológica, observa a existência de uma concepção da Sociologia e da ciência política burguesa que a considera um momento "disfuncional" que rompe bruscamente com o equilíbrio natural de um sistema ou, enquanto concepção prevalente, como uma crise que consiste numa série de traços particulares, resultando desta condensação de contradições no domínio político, que afetam tanto as relações de classe na sua política, como os aparelhos de Estado (POULANTZAS, 1978. p. 20-23).

11 "Chama-se crise a um momento de ruptura no funcionamento de um sistema, a uma mudança qualitativa em sentido positivo ou em sentido negativo, a uma virada de improviso, algumas vezes até violenta e não prevista no módulo normal segundo o qual se desenvolvem as interações dentro do sistema em exame" (PASQUINO, 2004, p. 303).
} 


\section{Hireitos}

Democracia

tado surge um momento de crise que mobiliza esforços dos cientista para resolução e ajuste das anomalias. Se porventura a crise perdura a tal ponto de causar uma revolução científica desponta um novo paradigma, que não é melhor que o primeiro, apenas atende, de maneira mais adequada, ao período histórico e social no qual está inserido.

Assim, quando o poder Judiciário (e seu paradigma adversarial) não consegue responder aos conflitos de seus usuários de maneira plausível e adequada, a crise irrompe, causando, entre outras coisas, o risco de que o jurisdicionado perca a crença no sistema de Justiça. Outra consequência é o surgimento de paradigmas alternativos/complementares que possam garantir a resposta adequada.

Argumentando nesse sentido, mas baseado na mudança de paradigma científico, Altvater (1999, p. 110) afirma:

Uma revolução científica, uma mudança de paradigmas científicos, acontece quando o novo "estilo de pensamento" - o novo "pensar coletivo" - forma uma nova "comunidade de discurso", ganhando hegemonia em questões epistemológicas de interesse comum (científico) e público.

Para que a mudança de paradigma ocorra, no entanto, as pessoas atingidas precisarão estar preparadas para absorvê-la, identificando o seu papel e as expectativas sociais no contexto inovador. Faz-se necessário, então, criar um ambiente jurídico/acadêmico que propicie uma atitude crítica e inconformista que a partir da observação do ontem e do hoje possa encaminhar o nascimento do novo paradigma com vistas para o amanhã. Essa mudança só poderá ocorrer se tiver como mola propulsora os "usuários do sistema de justiça". ${ }^{12}$ Estes últimos precisarão ser exaustivamente informados da crise/dificuldade e dos pontos de exaurimento que evidenciam a necessidade de rompimento com o paradigma atual para que se instale o novo.

As mudanças precisam partir dos próprios usuários do sistema de Justiça, na provocação e na organização de políticas públicas voltadas para a melhoria e adequação da prestação jurisdicional do Estado à conflitiva social. Essa proposição de novas políticas públicas deve levar em conta, além dos pontos de exaurimento do paradigma atual, as (des)vantagens e as possíveis implicações de uma quebra de paradigma. Além disso, a inovação dependerá de uma preparação de cunho psicológico para as mudanças que possa vir a gerar, especialmente aquelas que propõem um paradigma de autonomização e de responsabilização social (e não estatal) por atos e omissões.

Assim, a "resistência pode ser superada desde que as pessoas sejam educadas e preparadas antecipadamente para a mudança. A comunicação de idéias e do projeto ajuda as pessoas a perceberem a necessidade da mudança e a lógica inerente a ela" (CHIAVENATO, 1996, p. 252). Observa-se, pois, que a participação e o envolvimento de todos conduz à anuência, ao comprometimento e à legitimação da política pública proposta, o que é fundamental para que se alcance o reconhecimento social do novo paradigma.

\footnotetext{
${ }^{12}$ Aqui entendidos como todos aqueles que se encontram diretamente conectados ao sistema judicial, seja no exercício de sua profissão, inclusive na qualidade de jurisdicionado à espera da resposta estatal para suas demandas.
} 


\section{De Ontem Para Amanhã: a necessária/salutar quebra de paradigmas}

Mudar um paradigma, romper com o modelo dado, praticado e reconhecido, é ação difícil. Esse movimento somente pode ser conduzido pelos integrantes da sociedade que o reconhecerão e legitimarão. Essa dificuldade de ruptura e instalação do novo/diferente acontece em vários contextos e segmentos sociais. Dentro do Judiciário, a ruptura do modelo jurisdicional heterocompositivo na resolução de conflitos como hipótese única, legitimando outros mecanismos, a exemplo da autocomposição, mostrou ser uma empreitada difícil, na qual vislumbra-se que o paradigma atual (heterocomposição) encontra-se arraigado, tornando difícil a instauração, ainda que paralela, de um outro paradigma (autocomposição).

Tomando a área da saúde, mais especificamente aquela que objetiva prevenir doenças, observa-se que algumas rupturas aconteceram, trazendo grandes e positivas consequências, não sem deixar marcas históricas. Essas marcas foram impressas especialmente pela resistência com relação ao novo/diferente.

Essa afirmativa pode ser comprovada pela biografia do médico Ignaz Semmelweis, que trabalhava numa maternidade vienense, e que, nos idos de 1847, passou a sustentar, contrariando todos os conhecimentos médicos da época, que a infecção puerperal que acometia parturientes e jovens mães era consequência da transmissão das então chamadas "partículas cadavéricas. ${ }^{13 "}$ Semmelweis foi o primeiro na história médica que demonstrou que a febre puerperal (também conhecida como "febre infantil") era contagiosa e sua incidência poderia ser drasticamente reduzida por meio da aplicação adequada de regras de higiene, entre elas e principalmente, imposição de lavagem apropriada das mãos por cuidadores médicos. Embora atualmente comprovada, a descoberta de Semmelweis na época confrontou diretamente crenças da Ciência e da Medicina (ATAMAN;VATANOGLU-LUTZ;YILDINM, 2013, p. 35). ${ }^{14}$

Essa transmissão se dava, conforme Semmelweis, pelas mãos dos médicos e dos estudantes que se ocupavam de seccionar cadáveres sem lavar as mãos. Com essa conclusão, Semmelweis condenou todo o sistema científico da Medicina da época e proclamou que, para banir a febre puerperal dos hospitais, era necessária e salutar uma limpeza rigorosa das mãos, com uma solução de ácido clórico (THORWALD, 2010).

$\mathrm{Na}$ sua empreitada o médico comparou duas maternidades vienenses e percebeu que na primeira a taxa de mortalidade materna média era de $10 \%$. Na segunda maternidade a taxa era consideravelmente menor, com média de $4 \%$. Estes fatos eram conhecidos fora dos hospitais, pela população. As duas maternidades admitiram as parturientes em dias alternados. As mulheres imploravam para ser admitidas e terem seus bebês na segunda maternidade, devido à má reputação da primeira. Algumas parturientes preferiram ter seus filhos em casa ou nas ruas, fingindo um parto às pressas para não serem internadas na primeira maternidade. Assim, a primeira constatação de Semmelweis foi que a febre puerperal era

\footnotetext{
${ }^{13} \mathrm{Na}$ época não se tinha conhecimento da existência das bactérias. Semmelweis chamou "cadaverous particle" (ATAMAN; VATANOGLU-LUTZ; YILDINM, 2013, p. 36) essas partículas mortais.

14 "Ignaz Semmelweis (Figure 1) was the first physician in medical history who demonstrated that puerperal fever (also known as "childbed fever") was contagious and that its incidence could be drastically reduced by enforcing appropriate hand washing by medical care-givers (3). Although hugely successful; Semmelweis' discovery directly confronted the beliefs of science and medicine in his time" (ATAMAN; VATANOGLU-LUTZ; YILDINM, 2013, p. 35).
} 


\section{Humanos e}

Democracia

menos frequente nas mulheres que tinham seus filhos em casa ou a caminho do hospital do que naquelas que estavam internadas na primeira maternidade (ATAMAN; VATANOGLU-LUTZ; YILDINM, 2013, p. 36). ${ }^{15}$

A primeira maternidade, justamente aquela na qual a taxa de mortalidade materna por febre puerperal era maior, era um hospital-escola para estudantes de Medicina. Já a segunda era composta por um corpo de parteiras que realizavam os partos. A grande descoberta do agente causador da sepse aconteceu em 1847 com a morte de um colega e amigo de Semmelweis de nome Jakob Kolletschka, o qual foi acidentalmente ferido por um bisturi manuseado por um estudante durante a realização de uma autópsia. Pouco tempo depois Kolletschka caiu enfermo, com os mesmos sintomas das parturientes investigadas por Semmelweis, vindo a falecer (ELLIS, 2008).

Semmelweis identificou imediatamente uma conexão entre a contaminação de cadáveres e a febre puerperal. Então ele concluiu que os estudantes de Medicina realizavam autópsias e pela falta de higiene nas mãos transmitiam às parturiente os que ele chamou de "partículas cadavéricas". Por isso a primeira maternidade apresentava taxas tão altas de mortalidade, pois nela existia o trabalho dos estudantes, que além dos partos realizavam autópsias. Já na segunda maternidade os partos eram feitos por parteiras, inexistindo o contato cadavérico com as parturientes. As parteiras não se envolviam com autópsias (ATAMAN; VATANOGLU-LUTZ; YILDINM, 2013).

Os colegas médicos de Semmelweis não entenderam a importância da notícia e da descoberta da "infecção pelo contato" que se prestaria a "combater a proliferação mortífera das moléstias traumáticas infecciosas" (THORWALD, 2010, p. 233-234).

Ao relatar a descrença na proposição (lavar as mãos, simplesmente) do médico vienense, Henrique Estêvão Hartmann reconhece que:

Hoje, isto parece incompreensível; evidencia, porém, até a que ponto todos nós somos escravos de preconceitos arraigados, ou pelos consagrados pelo uso, e como nos custa aceitar qualquer inovação, tanto mais quando a novidade se nos afigura demasiado simples, para resolver problemas complexos (THORWALD, 2010, p. 234).

Ao longo do texto de Thorwald (2010) e em outros artigos científicos já publicados, fica claro que a ignorância, a aceitação da febre puerperal como fatalidade inevitável, eram conhecimentos e crenças que foram transmitidos a Semmelweis por seus mestres; ele e os colegas enfrentaram tais fatos como naturais até o momento em que passou a detectar que quando os partos eram demorados as parturientes, quase sem exceção, não escapavam da febre puerperal. Diante de tal constatação Semmelweis passou a buscar explicações (MARKEL, 2015).

\footnotetext{
${ }^{15}$ The First Clinic had an average maternal mortality rate due to puerperal fever of about $10 \%$. The Second Clinic rate was considerably lower, averaging less than $4 \%$. This fact was known outside the hospital. The two clinics admitted on alternate days but women begged to be admitted to the Second Clinic, due to the bad reputation of the First Clinic. Some women even preferred to give birth in the streets, pretending to have given sudden birth, which meant they would still qualify for the child care benefits without having been admitted to the clinic. Semmelweis was puzzled that puerperal fever was rare among women giving street births (ATAMAN; VATANOGLU-LUTZ; YILDINM, 2013, p. 36).
} 
Então, partindo da observação atenta da rotina do hospital, Semmelweis desvendou o segredo da transmissão das "partículas cadavéricas". Tal se dava "por meio das mãos e dos instrumentos dos médicos e cirurgiões, revelação que seria três decênios depois a pedra angular da assepsia" (THORWALD, 2010, p. 242). No dia 15 de maio de 1847 iniciava-se, pois, a luta fatídica da sua vida. Nessa data o médico mandou afixar na porta da clínica a determinação de que

A partir de hoje, 15 de maio de 1847, todo estudante, ou médico, proveniente da sala de anatomia é obrigado, antes de entrar nas salas da clínica obstétrica, a lavar as mãos com uma solução de ácido clórico, na bacia colocada na entrada. Esta disposição vigorará para todos. Sem exceção. I. F. Semmelweis (THORWALD, 2010, p. 241-242).

Nos dias subsequentes Semmelweis fez outra descoberta: além dos mortos que eram potenciais transmissores das "partículas cadavérias", os enfermos vivos também as podiam propagar, se fossem portadores de processos pútridos e purulentos.

O médico, incansável, ao fazer estas descobertas e ao pôr em prática a assepsia a partir da higienização das mãos com água e sabão, precisou suportar e combater a inércia dos estudantes e colegas de profissão. Exerceu vigilância para que lavassem as mãos e para que evitassem transmitir a infecção circulando entre pacientes vivos e mortos detentores das "partículas cadavéricas". Mais uma vez Semmelweis colheu má-vontade, ódio, escárnio, mas, não obstante todas as dificuldades, em seis anos de trabalho duro conseguiu que, de "933 parturientes, morressem apenas oito, o que significava menos de 1 por cento" (THORWALD, 2010, p. 247).

Por ser um homem de temperamento difícil, Semmelweis recusou-se a publicar suas descobertas por até 13 anos depois de tê-las feito, apesar de ter sido instado a fazê-lo repetidamente por aqueles que o apoiaram. A situação tornou-se ainda mais difícil quando ele lançou insultos grosseiros a alguns dos médicos mais poderosos do hospital que questionaram suas ideias. Tais explosões, por mais merecidas que fossem, nunca passaram despercebidas e muito menos impunes nos sóbrios salões da Medicina acadêmica. Semmelweis perdeu a chance de clinicar no Hospital Geral de Viena e, em 1850, viajou abruptamente para sua Budapeste, sem avisar nem mesmo aos seus colegas mais próximos. Somente em 1861 ele publicou seu trabalho, Die Aetiologie, der Begriff und die Prophylaxis des Kindbettfiebers, no qual explicou suas teorias (MARKEL, 2015).

O comportamento de Semmelweis tornou-se cada vez mais errático e ele finalmente foi trancafiado em um hospício no dia 30 de julho de 1865. Neste local ele morreu, duas semanas depois, em 13 de agosto, aos 47 anos. Os historiadores ainda discutem sobre o que causou a deterioração da saúde mental de Semmelweis e a sua morte subsequente. ${ }^{16}$

\footnotetext{
${ }^{16}$ Alguns apontam para uma operação realizada por Semmelweis, na qual ele se infectou com sífilis, o que também pode explicar sua loucura. Outros acreditam que ele desenvolveu envenenamento do sangue e sepsis enquanto preso no asilo, o que pode ter sido um caso desenfreado de doença bipolar. Mais recentemente, alguns têm afirmado que o obstetra tinha uma variante precoce da doença de Alzheimer e foi espancado até a morte no asilo por seus guardiões (MARKEL, 2015).
} 
O exame cadavérico, porém, revelou, simultaneamente com os sintomas anatômicos da paralisia, o mesmo quadro que ele tivera tantas vezes ante os olhos: inflamações e supurações em toda parte. $O$ primeiro homem que desvendou o segredo da sepsia e da assepsia, as bases em que se havia de erigir o futuro da cirurgia, morreu de sepsia (THORWALD, 2010, p. 251).

O timing profissional de Semmelweis não poderia ter sido pior. Ele fez sua descoberta principal entre 1846 e 1861, muito antes de a Medicina estar pronta para aceitá-la, no entanto, a partir de 1900, médicos e historiadores proferiram grandes elogios ao trabalho de Semmelweis. Atualmente, nos cursos de Medicina e de saúde pública, seu nome é proferido com grande reverência sempre que o tema diga respeito a lavar as mãos. Infelizmente, na sua época, ele foi ridicularizado. Era considerado, na melhor das hipóteses, excêntrico e, na pior, como um homem irado e instável, que deveria ser excluído da profissão. A verdade é que seus críticos estavam errados e Semmelweis pagou um preço alto dedicando sua vida, curta e conturbada, para vencer os limites do conhecimento médico-científico quebrando um paradigma até então instituído e melhorando a prestação dos serviços médicos em prol da nobre missão de salvar vidas.

A partir da história de Semmelweis, é preciso considerar que toda mudança rompe a rotina e impõe uma ruptura em relação ao passado. Por evidente, toda mudança traz uma crise para as organizações ao substituir subitamente o que era certo pelo incerto. Percebe-se que enquanto a não mudança proporciona significativo volume de acomodação e de ajustamento das pessoas à rotina diária, a mudança significa variações e alterações que passam a trazer incômodo, insegurança e incerteza (CHIAVENATO, 1996).

$\mathrm{Na}$ época de Semmelweis os paradigmas existentes já possuíam (tal como hoje possuem) o efeito de moldar profundamente o comportamento e a atitude das pessoas. Já se observava, assim como hoje ocorre, que existem maneiras diferentes mediante as quais os indivíduos ou grupos podem reagir à mudança/quebra de paradigma. Essas reações vão desde a resistência passiva, passando pela tentativa agressiva de sabotá-la ou pela sincera e profunda adesão.

No contexto das Ciências Sociais, mais precisamente no âmbito do Direito, essas mesmas reações são observadas quando o paradigma atual sofre alterações, sejam elas impostas por mudanças legislativas ou gradativamente alcançadas pelas transformações sociais. Assim aconteceu/acontece com relação aos meios de tratar conflitos, mais especificamente na última década, especialmente a partir da Resolução 125 do CNJ, que se tornou o primeiro documento a disciplinar a mediação como política pública judiciária de tratamento de conflitos. ${ }^{17}$

\footnotetext{
17 Importante considerar que a Resolução 125/2010 do CNJ menciona, em vários momentos, a expressão "política pública" nos seus "considerandos", no título do capítulo I, no artigo 60, inciso 1ㅇe e na introdução do Anexo III, porém em diversos momentos também se refere à política pública como uma "política judiciária nacional". Por isso, neste texto optou-se por trabalhar com a expressão "política pública" por se tratar de categoria mais ampla, que engloba a política judiciária nacional de tratamento adequado de conflitos.
} 


\section{Para Hoje? Para amanhã? Depois da crise um outro paradigma?}

Mais que um meio de acesso à Justiça, fortalecedor da participação social cidadã, a mediação é política pública ${ }^{18}$ judiciária que vem ganhando destaque e fomento do Ministério da Justiça, da Secretaria de Reforma do Judiciário e do CNJ brasileiros, uma vez que resta comprovada empiricamente sua eficiência no tratamento de conflitos. Prova disso é a Resolução 125/ 2010 do CNJ (alterada pela Emenda no 1/2013 e pela Emenda no 2/2016), que versa sobre a "Política Judiciária Nacional de Tratamento Adequado dos Conflitos". Na sequência foram promulgadas a Lei 13.140/2015 (conhecida como marco legal da Mediação), a Lei 13.105/2015 (Código de Processo Civil) e a Resolução 174/2016 do CSJT.

As resoluções e legislações mencionadas têm por objetivo tornar o acesso à Justiça adequado em termos qualitativos (exequibilidade de sentenças) e quantitativos (tempo do processo e congestionamento do Judiciário) e, principalmente, fomentar uma mudança de paradigma que importe na substituição do formato adversarial e litigante pelo consenso.

A mudança de paradigma ocorrida, no entanto, encontrou resistência nos contextos jurídico e social. A prática dos meios complementares de tratamento dos conflitos, entre eles a conciliação e a mediação, como formas de acesso à Justiça, ainda não foram absorvidas, demonstrando que, tal como nas descobertas e iniciativas do médico Semmelweis, a resistência à mudança de paradigma é um entrave significativo, ainda que a necessidade de ruptura e alteração esteja cientificamente comprovada. ${ }^{19}$

Observa-se que, assim como Semmelweis com os processos infecciosos, os atores e usuários do Judiciário têm se inquietado, por anos, com as dificuldades de absorver e de responder aos conflitos sociais de modo adequado. Essas dificuldades são expostas no formato das tão propaladas crises do Judiciário. Essas crises são de identidade e de eficiência (SPENGLER, 2016). A crise de identidade pode ser observada por um certo embaçamento do papel judicial como regulador central de conflitos, perdendo espaço para outros centros de poder, talvez mais aptos a lidar com a complexidade conflitiva atual, mais adequados em termos de tempo e espaço. Tal se dá porque o aparato judicial, para tratar os conflitos atuais, serve-se de instrumentos e de legislação muitas vezes ultrapassados, ainda que formalmente em vigor, com acanhado alcance e eficácia reduzida. Tal eficácia e alcance muitas vezes atingem somente os conflitos interindividuais, não extrapolando o domínio privado das partes, encontrando dificuldades quando instado a tratar de direitos coletivos ou difusos.

A crise de eficiência do sistema de Justiça brasileiro pode ser percebida a partir da constatação de que, uma vez impossibilitado de responder de modo eficiente à complexidade social e litigiosa diante da qual se depara, o Judiciário sucumbe perante a inovadora carga de tarefas a ele submetidas. Evidencia-se, então, o "flagrante descompasso entre a procura e a

\footnotetext{
18 "Política Pública é o programa de ação governamental que resulta de um processo ou conjunto de processos juridicamente regulados - processo eleitoral, processo de planejamento, processo de governo, processo orçamentário, processo legislativo, processo administrativo, processo judicial - visando coordenar os meios à disposição do Estado e as atividades privadas, para a realização de objetivos socialmente relevantes e politicamente determinados. Como tipo ideal, a política pública deve visar à realização de objetivos definidos, expressando a seleção de prioridades, a reserva de meios necessários à sua consecução e o intervalo de tempo em que se espera o atingimento dos resultados" (BUCCl, 2006, p. 39).

${ }^{19} \mathrm{O}$ site do CNJ e os dados lá expostos demonstram cabalmente tais argumentos. Nesse sentido ver <http://www.cnj.jus.br/ programas-e-acoes/pj-justica-em-numeros>.
} 


\section{Hireitos \\ Humanos e}

Democracia

oferta de serviços judiciais, em termos tanto qualitativos quanto quantitativos" (FARIA, 2005, p. 11). Esse descompasso entre a oferta e a procura gera uma frustração geral, decorrente da morosidade e da pouca eficiência dos serviços judiciais, quando não da sua simples negação aos segmentos desfavorecidos da população, que ainda precisam lidar com a diferença entre a singela concepção de Justiça que possuem e a complexidade burocrático/formal dos ritos processuais. ${ }^{20} \mathrm{~A}$ conjugação dessas duas circunstâncias acaba provocando o desprezo e o descrédito do cidadão comum pela Justiça, afastando-o dela, muitas vezes.

Essa descrença na Justiça se dá não só pela distância entre o cidadão comum, os ritos e a linguagem que envolvem os processos judiciais, mas também pelo tempo percorrido pelos procedimentos (tradicionalmente longos), pela inadequação das decisões vertidas diante da complexidade dos litígios e pela impossibilidade de seu cumprimento. O que se verifica, então, é a desconexão entre o aparelho judicial e o sistema político e social, distanciando-se a lei (e, por conseguinte, sua interpretação e sua aplicação) da sociedade na qual se encontra inserida, não correspondendo, assim, à expectativa de tratamento adequado aos conflitos.

Permeada por todos estes pontos de ruptura, a crise de identidade aponta para outros três grandes problemas que, mesmo em menor escala, influenciam também a crise de eficiência e que podem, primeiramenete, ser resumidos a uma desconexão entre a realidade social, econômica e cultural da qual são advindos os conflitos e a realidade legal obsoleta e ultrapassada. Por outro lado, a legislação mais moderna (assim considerada porque editada a partir de concepções contemporâneas do Direito), aptas a lidar não só com conflitos individuais mas também coletivos, que envolvem questões de natureza distributiva ou social, esbarram numa cultura profissional dos operadores do Direito que sofrem de um excessivo individualismo e formalismo. Esse individualismo traduz-se pela convicção de que a parte precede o todo, ou seja, de que os direitos do indivíduo estão acima dos direitos da comunidade; como o que importa é o mercado, espaço no qual as relações sociais e econômicas são travadas, o individualismo tende a transbordar em atomismo: a magistratura é treinada para lidar com as diferentes formas de ação, mas não consegue ter um entendimento preciso das estruturas socioeconômicas nas quais elas são travadas. Já o formalismo decorre do apego a um conjunto de ritos e procedimentos burocratizados e impessoais, justificados em nome da certeza jurídica e da segurança do processo (FARIA, 2001).

Tal como já havia sido observado por Semmelweis, nos idos do século 18, os atores e usuários da Justiça percebem a necessidade de mudança e de criação de um novo paradigma. Em Viena, na época de Semmelweis, a necessidade salutar de mudança foi detectada pelo número excessivo de óbitos, posteriormente foi observada de perto e então as primeiras medidas instituídas e testadas para finalmente os resultados iniciais serem percebidos. No Brasil, quando se fala de crise da jurisdição, o conhecimento comum que envolve população

\footnotetext{
${ }^{20}$ Por isso, uma das formas de possibilitar o acesso à Justiça, aproximando o cidadão de seus ritos, passa pela necessidade dos "juristas reconhecerem que as técnicas processuais servem a funções sociais; que as cortes não são a única forma de solução de conflitos a ser considerada e que qualquer regulamentação processual, inclusive a criação ou o encorajamento de alternativas ao sistema judiciário formal, tem um efeito importante sobre a forma como opera a lei substantiva - com que freqüência (sic) ela é executada, em benefício de quem e com que impacto social. Uma tarefa básica dos processualistas modernos é expor o impacto substantivo dos vários mecanismos de processamento de litígios. Eles precisam, consequentemente (sic), ampliar sua pesquisa para mais além dos tribunais e utilizar métodos de análise da sociologia, da política, da psicologia e da economia, e ademais, aprender através de outras culturas" (CAPPELLETTI; GARTH, 1988. p. 13).
} 
e juristas e que afirma que "as coisas não vão bem" encontra-se comprovado pelos dados e informações dispostos no "Relatório Justiça em Números", do CNJ, que demonstra, dentre outras coisas, um número excessivo de processos e um tempo longo - desde seu ajuizamento até decisão final - que é traduzido pela taxa de congestionamento.

Foi diante dessa realidade que se buscaram caminhos para a mudança de paradigma, substituindo a cultura do litígio pela do consenso. A mediação é um desses caminhos e tem por objetivo proporcionar a guinada, oferecendo à população um meio de lidar com seus conflitos de maneira consensuada, democrática e responsável. A mudança de paradigma, porém, que objetiva instaurar uma nova cultura, precisa ser avaliada. Como toda política pública, passados oito anos de sua criação, é chegada a hora de ser avaliada objetivando verificar se cumpriu com seu propósito, ou seja, se disseminou a cultura de pacificação social conforme o previsto no artigo 2 da Resolução 125/2010 do CNJ.

As dúvidas permanecem, pois, até o momento, as pesquisas não foram suficientemente hábeis e seguras para demonstrar a eficiência da Resolução e do paradigma por ela proposto, bem como assegurar que uma nova cultura (pacificação social) se instaurou em termos de tratamento dos conflitos no Brasil. Importante aqui fazer a conexão com a Medicina e com a mudança cultural instaurada por Semmelweis com o hábito simples de lavar as mãos. No final do século 18, a mudança de paradigma foi gradativa e tortuosa, foram necessários alguns anos para que a sociedade entendesse a importância da assepsia.

Ao que tudo indica, no tratamento dos conflitos a mudança de paradigma e a instauração de uma outra cultura não serão diferentes. O caminho já percorrido foi longo e não se avistam, ainda, grandes resultados. Talvez seja uma questão de tempo, talvez seja uma questão de consciência, de entender que a mudança é salutar e necessária para afrontar a crise instaurada na jurisdição brasileira.

Assim, a conduta diferenciada daquela atualmente vista e praticada na maioria das lides processuais precisa ser semeada e cultivada, pois ela faz parte daquilo que se declara aos quatro ventos: a necessidade de uma mudança de paradigma, substituindo a cultura da sentença pela cultura da pacificação social. Para que isso aconteça o investimento começa pelo conhecimento e aceitação da mediação. A principal vantagem é a reeducação dos conflitantes, dando a eles a noção de que podem (e devem!) tratar seus conflitos de maneira direta e pacífica, sem a intervenção do Estado, ultrapassando o paradigma da sentença para estabelecer e consolidar o paradigma do consenso e da efetiva pacificação social.

\section{Conclusão}

O presente texto teve como cenário as alterações médicas realizadas por Semmelweiss que mudaram o paradigma de prevenção e tratamento de doenças, introduzindo a cultura de assepsia mediante o simples ato de lavar as mãos. Comparando essa reviravolta realizada em Viena no século 18 e a criação e introdução de políticas públicas de tratamento dos conflitos, no Brasil, especialmente a partir de 2010, com a Resolução 125 do CNJ, o presente texto teve por tema a mudança do atual paradigma jurídico brasileiro introduzindo-se uma nova cultura na prevenção e administração dos conflitos. 
Partindo do tema mencionado o problema de pesquisa norteou a construção das principais conclusões. A pesquisa realizada cumpriu rigorosamente o objetivo proposto e seguindo a metodologia escolhida respondeu ao problema confirmando a hipótese apresentada. Assim, observa-se que é possível tecer comparações e inclusive servir-se do exemplo de Semmelweis, promovendo a quebra do paradigma atual e uma mudança da cultura jurídica no que diz respeito ao modo como vêm sendo tratados os conflitos no país. Fica claro, porém, que se torna imperioso evitar alguns equívocos cometidos pela sociedade médica da época de Semmelweis, no que dizia respeito à observação e à valorização de suas descobertas.

Nesse sentido, os juristas e os usuários do sistema de Justiça brasileiros precisam recepcionar com cuidado e aplicar com seriedade as propostas que possibilitarão a quebra de paradigma e a introdução e disseminação da cultura de pacificação social. O cuidado diz respeito aos princípios éticos e basilares da mediação que, mais do nunca, precisam ser observados. Além disso, faz-se necessário que o novo paradigma seja tratado com responsabilidade, sem grandes arroubos de entusiasmo, evitando-se uma análise e uma aplicação rasa e equivocada.

Essa afirmativa se dá, especialmente, porque até o momento não existem resultados, cientificamente comprovados, da eficiência e da receptividade do novo paradigma junto ao cenário brasileiro. Enquanto tal não ocorre fala-se do senso comum que aponta avanços e retrocessos, mas principalmente anseia-se por evitar que aconteça com a mediação e com os seus idealizadores o mesmo que ocorreu com a assepsia e com o médico vienense. Espera-se evitar que a mediação e seus procedimentos sejam combalidos pelo mesmo mal que pretendem combater, tal como ocorreu com Semmelweis. O novo paradigma deve instituir uma cultura jurídica que permita ao cidadão lidar com seus conflitos de modo consensuado, pessoalizado, responsável e democrático. Espera-se que o novo paradigma não sofra e não seja soçobrado pelo mal que pretendia evitar: a formalidade, a burocracia, a lentidão e o acúmulo de demandas.

Além disso, torna-se necessário não descuidar dos princípios da mediação e de sua base teórica, para fins de efetivamente instituir uma outra cultura mediante a mudança de paradigma que cumpra com seu propósito, que propicie um acesso à Justiça adequado em termos qualitativos e quantitativos e, principalmente, que permita a efetiva pacificação social. Para que essa conscientização ocorra, primeiramente deve-se criar meios para cumprir a política pública proposta e posteriormente para avaliá-la, efetivamente, objetivando detectar pontos de exaurimento, gargalos e dificuldades. Esse cuidado evitará que se ponha a perder o novo paradigma antes mesmo de ele ser experimentado, difundido e praticado. A avaliação permitirá ajustes, melhorias que gerem eficiência e que possam evitar aquilo que na triste história de Semmelweis se pôde detectar: primeiramente uma descrença terrível, posteriormente a resistência e só então, quando comprovados os benefícios da assepsia, a adesão ao seu uso. Enquanto esse caminho foi traçado, no entanto, o que de pior aconteceu ao seu médico idealizador: Semmelweis morreu, aos 47 anos, internado como louco, vítima de uma terrível infecção, justamente o mal que pretendeu combater e evitar! O médico, sozinho, propôs uma mudança radical e morreu desacreditado. 
Em termos de mudança de cultura pela substituição de paradigma quanto ao tratamento de conflitos no Brasil é preciso fazer um caminho menos tortuoso e mais rápido do que aquele percorrido por Semmelweis. É preciso evitar que a mediação (que já nasceu debilitada) tenha dificuldades para se desenvolver e que venha a falecer antes mesmo do reconhecimento de suas possibilidades e da mudança que poderá proporcionar.

\section{Referências}

ALTVATER, E. Os desafios da globalização e da crise ecológica para o discurso da democracia e dos direitos humanos. In: HELLER, A. et al. (Org.). A crise dos paradigmas e os desafios para o século XXI. Rio de Janeiro: Contraponto, 1999.

ARNAUD, André-Jean. O Direito traído pela filosofia. Tradução Wanda de Lemos Capeller e Luciano Oliveira. Porto Alegre: Sergio Antonio Fabris, 1991.

ATAMAN, Ahmet Dogan; VATANOGLU-LUTZ, Ermine Elif; YILDINM, Gazi. Medicine in stamps - Ignaz Semmelweis and Puerperal Fever. Journal of the Turkish-German Gynecological Association, Istambul, n. 14, p. 35-39, 2013. BOBBIO, Norberto; MATTEUCCI, Nicola; PASQUINO, Gianfranco. Dicionário de política. Tradução Carmem C. Varriale et al. 12. ed. Brasília: Universidade de Brasília, 2004.

BOLZAN DE MORAIS, José Luis. Mediação e arbitragem: alternativas à jurisdição. Porto Alegre: Livraria do Advogado, 1999. p. 99-100.

BOLZAN DE MORAIS, José Luis; SPENGLER, Fabiana Marion. Mediação e arbitragem: alternativas à jurisdição. 3. ed. Porto Alegre: Livraria do Advogado, 2012.

BUCCI, Maria Paula Dallari. O conceito de política pública em direito. In: BUCCI, Maria Paula Dallari (Org.). Políticas públicas: reflexões sobre o conceito jurídico. São Paulo: Saraiva, 2006.

CAPPELLETTI, Mauro; GARTH, Bryant. Acesso à justiça. Tradução Ellen Gracie Northfleet. Porto Alegre: Sérgio Antônio Fabris, 1988.

CASELLI, Gian Carlo; PEPINO, Livio. A un cittadino che non crede nella giustizia. Bari-Roma: Laterza, 2005.

CHASE, Oscar G. Direito, cultura e ritual: sistemas de resolução de conflito no contexto da cultura comparada. Tradução Sérgio Arenhardt e Gustavo Osna. 1. ed. São Paulo: Marcial Pons, 2014.

CHIAVENATO, Idalberto. Os novos paradigmas: como as mudanças estão mexendo com as empresas. São Paulo, Atlas, 1996. 319p.

CONSELHO NACIONAL DE JUSTIÇA (CNJ). Relatório Justiça em Números. 2015, p. 37. Disponível em: <http:// www.cnj.jus.br/programas-e-acoes/pj-justica-em-numeros>. Acesso em: 13 out. 2016.

Disponível em: <http://www.cnj.jus.br/programas-e-acoes/pj-justica-em-numeros>. Acesso em: 13 out. 2016.

CORSI, Giancarlo; ESPOSITO, Elena; BARALDI, Claudio. Glosario sobre la teoría social de Niklas Luhmann. Traducción Miguel Romero Pérez e Carlos Villalobos. México: Iberoamericana, 1996.

DAHRENDORF, Ralf. Homo sociologicus: ensaio sobre a história, o significado e a crítica da categoria social. Tradução Manfredo Berger. Rio de Janeiro: Tempo Brasileiro, 1991.

DICIONÁRIO ON-LINE DE PORTUGUÊS. Cultura. Disponível em: <https://www.dicio.com.br/cultura>. Acesso em: 15 maio 2017.

ELIAS, Norbert. A Sociedade de Corte: investigação sobre a sociologia da realeza e da aristocracia de corte. Rio de Janeiro: Zahar, 2001. 312p.

ELLIS, Harold. Ignaz Semmelweis: Tragic pioneer in the prevention of puerperal sepsis. British Journal os Hospital Medicine, Londres, vol. 69, n. 6, p. 358, june 2008.

FARIA, José Eduardo. O poder Judiciário no Brasil: paradoxos, desafios e alternativas. Brasília: Conselho da Justiça Federal, 1995.

O poder Judiciário nos universos jurídico e social: esboço para uma discussão de política judicial compa-

rada. In: Revista Serviço Social e Sociedade, ano XXII, n. 67, set. 2001.

A crise do Judiciário no Brasil: notas para a discussão. In: SARLET, Ingo Wolgang. Jurisdição e direitos fundamentais. Anuário 2004/2005. Porto Alegre: Livraria do Advogado/Ajuris: 2005.

GARAPON, Antoine; PAPAPOULOS, Ioannis. Julgar nos Estados Unidos e na França. Cultura Jurídica Francesa e Common Law em uma perspectiva comparada. Trad. Virgínia Vasconcelos. Rio de Janeiro: Lumen Juris, 2008.

KUHN, Thomas. S. A estrutura das revoluções cientificas. São Paulo: Perspectiva, 1991. 
MARKEL, Howard. In 1850, Ignaz Semmelweis saved lives with three words: wash your hands. PBS NEWUSHOUR. Maio de 2015. Disponível em: <http://www.pbs.org/newshour/updates/ignaz-semmelweis-doctor-prescribed-hand-washing/>. Acesso em: 18 maio 2017.

MARQUES, Ruy Garcia. Preparação para o ato operatório I - Assepsia e Anti-asspesia: conceituação. In: MARQUES, Ruy Garcia (Org.). Técnica operatória e cirúrgica. Rio de Janeiro: Guanabara Koogan, 2005.

MUSHAKOJI, K. Em busca de uma nova aliança anti-hegemônica. In: HELLER, A. et al. A crise dos paradigmas em ciências sociais e os desafios para o século XXI. Rio de Janeiro: Contraponto, 1999.

PASQUINO, Gianfranco. Crise. In: BOBBIO, Norberto; MATTEUCCI, Nicola; PASQUINO, Gianfranco. Dicionário de política. Tradução Carmen V. Varriale et al. Coordenador e tradutor João Ferreira. Revisão geral João Ferreira e Luís Guerreiro Pinto Cascais. 12. ed. Brasília: Editora Universidade de Brasília, 2004. V. 1.

POULANTZAS, Nicos. As transformações atuais do Estado. A crise política e a crise do Estado. In: POULANTZAS, Nicos. A crise do Estado. Tradução José Saramago. Braga: Pax, 1978.

RESTA, Eligio. Tempo e processo. Tradução Fabiana Marion Spengler. Santa Cruz do Sul: Essere nel Mondo, 2014. Disponível em: <www.esserenelmondo.com>SPENGLER, Fabiana Marion. Da jurisdição à mediação: por uma outra cultura no tratamento dos conflitos. 2. ed. Ijuí: Ed. Unijuí, 2016.

THORWALD, Jurgen. O século dos cirurgiões: conforme documentos de meu avô, o cirurgião H. E. Hartman. 1. ed. São Paulo: Leopardo Editora, 2010. 359p.

TOURAINE, Alain. Um novo paradigma: para compreender o mundo de hoje. 4. ed. Petrópolis, RJ: Vozes, 2011. $261 p$.

VENTURA, Deisy. Monografia jurídica: uma visão prática. Porto Alegre: Livraria do Advogado, 2000. 